\title{
PENENTUAN PORTOFOLIO SAHAM OPTIMAL MENGGUNAKAN ALGORITMA GENETIKA
}

\author{
Eka Lestari, Evy Sulistianingsih, Nurfitri Imro'ah
}

\begin{abstract}
INTISARI
Investor akan dihadapkan oleh keuntungan dan risiko dalam melakukan investasi. Untuk mengurangi risiko tersebut, investor dapat melakukan diversifikasi yaitu mengalokasikan dana ke beberapa saham sehingga terbentuk portofolio saham. Algoritma Genetika merupakan teknik yang diadopsi dari proses evolusi alam yang digunakan untuk melakukan pencarian penyelesaian optimal atas sejumlah penyelesaian masalah yang mungkin. Penelitian ini, mengimplementasikan Algoritma Genetika untuk memperoleh portofolio saham yang dapat memberikan keuntungan yang maksimal dan risiko tertentu. Parameter yang digunakan dalam Algoritma Genetika yaitu ukuran populasi (pop size) sebanyak 50 kromosom, probabilitas crossover $60 \%$ dan probabilitas mutasi sebesar 10\%. Data yang digunakan adalah data penutupan harga saham bulanan indeks LQ 45 periode Januari 2010 sampai Juni 2018. Berdasarkan hasil analisis, Algoritma Genetika lebih optimal dibandingkan dengan perhitungan manual menggunakan Single Index Model dalam menentukan portofolio saham karena keuntungan yang diperoleh lebih besar dan risiko lebih kecil. Fitness terbesar dari tiga generasi diperoleh sebesar 0,1122 dengan keuntungan 0,0081 dan risiko 0,0719. Sedangkan keuntungan dan risiko berdasarkan perhitungan manual menggunakan Single Index Model diperoleh yaitu 0,0075 dan 0,0746 .
\end{abstract}

Kata Kunci: Algoritma Genetika, Offspring, Crossover, Mutasi, Single Index Model

\section{PENDAHULUAN}

Investasi merupakan komitmen untuk melakukan penempatan sejumlah dana pada saat ini dengan harapan memperoleh keuntungan di masa mendatang [1]. Investasi juga diartikan sebagai hasil penundaan konsumsi sekarang untuk konsumsi di masa mendatang. Dalam melakukan investasi, investor dihadapkan oleh keuntungan dan risiko. Tujuan dari investasi adalah memperoleh return yang maksimum dan risiko yang minimum. Untuk meminimumkan risiko tersebut, investor dapat melakukan diversifikasi. Diversifikasi merupakan kegiatan yang dilakukan untuk mengalokasikan dana investasi ke berbagai sekuritas atau dikenal dengan portofolio. Portofolio merupakan kombinasi atau gabungan sekumpulan aset, baik berupa aset riil maupun aset finansial yang dimiliki investor. Pembentukan portofolio saham menyebabkan sulitnya investor dalam memilih sekuritas dan proporsi dana yang akan dialokasikan untuk memperoleh portofolio saham optimal [2].

Algoritma Genetika merupakan teknik yang diadopsi dari proses evolusi alam yang dirancang untuk melakukan simulasi proses-proses dalam sistem alam yang dicetuskan oleh Charles Darwin yaitu prinsip genetika dan seleksi alam. Algoritma Genetika ditemukan melalui sebuah penelitian oleh John Holland tahun 1975 di Universitas Michigan, Amerika Serikat dan dipopulerkan oleh muridnya yaitu Goldberg [3]. Algoritma Genetika digunakan untuk melakukan pencarian atas sejumlah penyelesaian yang mungkin menjadi solusi optimal dari suatu permasalahan. Populasi awal dalam Algoritma Genetika dibangkitkan secara acak, kemudian kromosom-kromosom dalam populasi tersebut dievaluasi dengan menggunakan fungsi fitness. Bentuk fungsi fitness yang dibentuk sesuai dengan masalah yang akan dioptimasi. Nilai fitness menyatakan tingkat kebugaran atau kualitas kromosom dalam populasi. Semakin tinggi nilai fitness sebuah kromosom maka semakin tinggi pula peluang kromosom tersebut dilanjutkan dalam generasi selanjutnya. Selanjutnya proses pembentukan offspring melalui dua operator Algoritma Genetika yaitu crossover (penyilangan) dan mutasi. Banyaknya kromosom yang akan mengalami proses crossover dan mutasi ditentukan oleh probabilitas crossover dan probabilitas mutasi. Operator crossover digunakan untuk menghasilkan offspring yang mewarisi sifat-sifat induknya sedangkan operator mutasi digunakan untuk menghasilkan offspring yang mengubah sifat-sifat dari induknya. Kromosom-kromosom pada populasi awal dan hasil dari 
operator Algoritma Genetika selanjutnya diseleksi sehingga jumlah populasi awal dan populasi setiap generasi bernilai konstan. Proses-proses tersebut dilakukan secara terus-menerus sampai kriteria berhenti yang digunakan [4].

Analisis data dilakukan dengan menghitung return dan expected return masing-masing saham serta melakukan uji normalitas return saham-saham tersebut. Selanjutnya, perhitungan manual menggunakan Single Index Model dengan membandingkan nilai ERB masing-masing saham dengan nilai $C$ ut off Point $\left(C^{*}\right)$. Jika nilai $E R B \geq C^{*}$ maka saham tersebut terpilih sebagai kandidat pembentuk portofolio saham optimal [5]. Saham-saham yang terpilih selanjutnya dilanjutkan dalam proses Algoritma Genetika. Kemudian menghitung bobot portofolio, return portofolio dan risiko portofolio saham berdasarkan Single Index Model. Siklus-siklus dalam Algoritma Genetika dimulai dengan membangkitkan populasi awal secara acak sesuai dengan parameter kontrol pop size yang digunakan yaitu sebanyak 50 kromosom. Selanjutnya mengevaluasi kromosom-kromosom tersebut dengan menghitung nilai fitness. Nilai fitness diperoleh dari rasio antara expected return portofolio dengan risiko portofolio berdasarkan Single Index Model. Setelah tahap evaluasi, selanjutnya dilakukan tahap crossover dan tahap mutasi. Parameter kontrol yang digunakan pada tahap crossover adalah $60 \%$ artinya terdapat $60 \%$ kromosom dalam populasi akan mengalami proses crossover. Tahap crossover dilakukan dengan menggunakan metode extended intermediate crossover. Setelah tahap crossover, selanjutnya dilakukan tahap mutasi. Parameter kontrol yang digunakan pada tahap mutasi adalah $10 \%$ artinya terdapat $10 \%$ kromosom dalam populasi akan mengalami proses mutasi. Tahap mutasi dilakukan dengan mengubah satu isi gen dari sebuah kromosom. Tahap-tahap dalam Algoritma Genetika dilakukan secara berulang-ulang sampai dengan kriteria berhenti yang digunakan yaitu generations atau berhenti pada generasi yang telah ditentukan. Pada penelitian ini, sampai generasi ketiga. Setelah itu, membandingkan hasil return portofolio dan risiko portofolio yang diperoleh berdasarkan Algoritma Genetika berdasarkan nilai fitness tertinggi dengan Single Index Model. Jika return portofolio yang diperoleh lebih besar dan risiko portofolio yang diperoleh Algoritma Genetika lebih kecil dari perhitungan manual menggunakan Single Index Model, maka diperoleh portofolio saham optimal berdasarkan Algoritma Genetika.

\section{RETURN SAHAM}

Return merupakan imbalan atas keberanian investor dalam menanggung risiko atas investasi yang dilakukan sehingga return menjadi faktor yang memotivasi investor untuk berinvestasi [6]. Dalam penelitian ini, perhitungan return menggunakan continuously compounding return (log return) yaitu [2]:

$$
R_{i t}=\ln \left(\frac{S_{i(t+1)}}{S_{i t}}\right)
$$

dengan $R_{i t}$ adalah realized return saham $i$ pada periode $t, S_{i(t+1)}$ harga saham $i$ pada periode $t+1$, dan $S_{i t}$ adalah harga saham $i$ pada periode $t$.

\section{UJI NORMALITAS KOLMOGOROV-SMIRNOV}

Misalkan $x_{1}, x_{2}, \ldots, x_{n}$ adalah sampel random berukuran $n$ dari suatu populasi dengan fungsi distribusi $F(x)$. Andaikan $F_{0}(x)$ adalah fungsi teoritik atau suatu fungsi distribusi tertentu dan akan diuji [7]:

$$
\begin{array}{ll}
\mathrm{H}_{0}: F(x)=F_{0}(x) \text { untuk semua } x & \text { (databerdistribusitertentu) } \\
\mathrm{H}_{1}: F(x) \neq F_{0}(x) \text { untuk suatu } x & \text { (data tidak berdistribusi tertentu) }
\end{array}
$$

Uji Kolmogorov-Smirnov dilakukan dengan menggunakan statistik uji:

$$
D=\sup _{-\infty<x<\infty}\left|F_{n}(x)-F_{0}(x)\right|
$$

dengan $F_{n}(x)$ adalah fungsi distribusi empirik berdasarkan sampel random $x_{1}, x_{2} \ldots x_{n} . \mathrm{H}_{0}$ ditolak jika nilai $D>D_{n, \alpha}$, dengan $D_{n, \alpha}$ merupakan nilai kritik uji Kolmogorov-Smirnov. 


\section{SINGLE INDEX MODEL}

Teori Single Index Model digunakan untuk menyederhanakan perhitungan pada model Markowitz [8]. Return saham dari Single Index Model yaitu sebagai berikut [9]:

$$
R_{i}=\alpha_{i}+\beta_{i} R_{m}+e_{i}
$$

dengan $R_{i}$ merupakan return saham ke- $i, \alpha_{i}$ merupakan komponen return saham yang tidak dipengaruhi oleh perubahan pasar, $\beta_{i}$ ukuran sensitivitas return saham akibat perubahan return indeks pasar dan $R_{m}$ merupakan return indeks pasar.

Asumsi-asumsi dalam Single Index Model yaitu [9]:

i. Rata-rata $e_{i}$ adalah nol atau $E\left[e_{i}\right]=0$

ii. Kesalahan residu $\left(e_{i}\right)$ tidak berkovarians dengan return indeks pasar $\left(R_{m}\right)$ atau

$$
E\left[e_{i}\left(R_{m}-\bar{R}_{m}\right)\right]=0
$$

iii. Residual saham ke- $i$ dan kesalahan residu saham ke- $j$ tidak berkovarians atau $E\left[e_{i} e_{j}\right]=0$, untuk $i \neq j$

iv. Varians $e_{i}$ adalah $E\left[e_{i}^{2}\right]=\sigma_{e_{i}}^{2}$

v. Varians $R_{m}$ adalah $E\left[\left(R_{m}-\bar{R}_{m}\right)^{2}=\sigma_{m}^{2}\right.$

Persamaan $\alpha_{i}$ dan $\beta_{i}$ diperoleh dengan menggunakan metode ordinary least square, yaitu:

$$
\begin{gathered}
\alpha_{i}=\bar{R}_{i}-\beta_{i} \bar{R}_{m} \\
\beta_{i}=\frac{n \sum_{t=1}^{n} R_{i t} R_{m t}-\sum_{t=1}^{n} R_{i t} \sum_{t=1}^{n} R_{m t}}{n \sum_{t=1}^{n} R_{m t}^{2}-\left(\sum_{t=1}^{n} R_{m t}\right)^{2}}
\end{gathered}
$$

EXPECTED RETURN SAHAM, VARIANS RETURN SAHAM DAN KOVARIANS ANTAR SAHAM SINGLE INDEX MODEL

Berdasarkan asumsi-asumsi pada Single Index Model, diperoleh persamaan expected return saham, varians return saham dan kovarians antar return saham berdasarkan Single Index Model, yaitu [9]:

$$
\bar{R}_{i}=\alpha_{i}+\beta_{i} \bar{R}_{m}
$$

dengan $\bar{R}_{i}$ merupakan expected return saham ke-i dan $\bar{R}_{m}$ merupakan expected return indeks pasar.

$$
\sigma_{i}^{2}=\beta_{i}^{2} \sigma_{m}^{2}+\sigma_{e_{i}}^{2}
$$

dengan $\sigma_{i}^{2}$ merupakan varians saham ke- $i, \sigma_{m}^{2}$ merupakan varians indeks pasar dan $\sigma_{e_{i}}^{2}$ merupakan varians residual saham ke- $i$.

$$
\sigma_{i j}=\beta_{i} \beta_{j} \sigma_{m}^{2}
$$

dengan $\sigma_{i j}$ merupakan kovarians return saham ke-i dan return saham ke-j.

\section{PENENTUAN PORTOFOLIO SAHAM OPTIMAL BERDASARKAN SINGLE INDEX MODEL}

Kesulitan yang dihadapi investor dalam membentuk portofolio saham adalah memilih saham yang akan dijadikan sebagai alternatif untuk berinvestasi dan proporsi dana yang akan dialokasikan pada saham tersebut. Dengan menggunakan Single Index Model, investor dapat memperoleh saham-saham sebagai penyusun portofolio dari sekian banyak saham yang ada untuk memperoleh return yang optimal dengan memilih nilai excess return to beta (ERB) setiap saham yang tinggi. Untuk menentukan nilai $E R B$ yang dikategorikan tinggi, maka diperlukan sebuah titik pembatas yaitu Cut off Point $\left(C^{*}\right)$. Nilai $E R B$ diperoleh dengan menggunakan persamaan sebagai berikut [9]:

$$
E R B_{i}=\frac{\left(\bar{R}_{i}-R_{F}\right)}{\beta_{i}}
$$

dengan $R_{F}$ merupakan return bebas risiko. Nilai $C^{*}$ merupakan nilai $C$ ut off Rate $\left(C_{i}\right)$ tertinggi dari setiap saham. Nilai $C_{i}$ diperoleh dengan menggunakan persamaan sebagai berikut [5]: 


$$
C_{i}=\sigma_{m}^{2} \sum_{j=1}^{k} Z_{j} \beta_{j}=\frac{\sigma_{m}^{2} \sum_{j=1}^{k} \frac{\left(\bar{R}_{j}-R_{F}\right) \beta_{j}}{\sigma_{e_{j}}^{2}}}{1+\sigma_{m}^{2} \sum_{j=1}^{k} \frac{\beta_{j}^{2}}{\sigma_{e_{j}}^{2}}}
$$

Bobot portofolio berdasarkan Single Index Model, dapat diperoleh dengan menggunakan persamaan sebagai berikut [5]:

$$
w_{i}=\frac{Z_{i}}{\sum_{i=1}^{n} Z_{i}}
$$

dengan

$$
Z_{i}=\frac{\beta_{i}}{\sigma_{e_{i}}^{2}}\left(\frac{\bar{R}_{i}-R_{F}}{\beta_{i}}-C_{i}\right)
$$

Expected return portofolio dan risiko portofolio berdasarkan Single Index Model diperoleh menggunakan persamaan sebagai berikut [5]:

$$
\begin{aligned}
& \bar{R}_{p}=\sum_{i=1}^{n} w_{i} \alpha_{i}+\left(\sum_{i=1}^{n} w_{i} \beta_{i}\right) \bar{R}_{m}=\alpha_{p}+\beta_{p} \bar{R}_{m} \\
& \sigma_{p}^{2}=\left(\sum_{i=1}^{n} w_{i} \beta_{i}\right)^{2} \sigma_{m}^{2}+\left(\sum_{i=1}^{n} w_{i} \sigma_{e_{i}}\right)^{2}=\beta_{p}{ }^{2} \sigma_{m}^{2}+\left(\sum_{i=1}^{n} w_{i} \sigma_{e_{i}}\right)^{2}
\end{aligned}
$$

\section{SIKLUS ALGORITMA GENETIKA}

Algoritma genetika merupakan cabang dari metode heuristik untuk menentukan solusi optimal dari sekumpulan solusi permasalahan yang diselesaikan. Algoritma Genetika diterapkan dalam beberapa persoalan antara lain Travelling Salesman Problem (TSP), Scheduling, Vehicle Routing, Group Technology, Facility Layout, dan Location Allocation karena telah diuji mampu memberikan solusi optimal dalam kasus optimasi [10]. Siklus-siklus dalam Algoritma Genetika yaitu sebagai berikut:

\section{Pembentukan Kromosom}

Kromosom menyatakan suatu solusi atas permasalahan yang diselesaikan. Pembentukan kromosom dalam penelitian ini menggunakan metode real coded [11]. Kromosom tersusun atas gen-gen sebanyak tiga gen. Gen-gen merupakan saham-saham yang terpilih menjadi kandidat portofolio saham optimal berdasarkan Single Index Model. Kromosom sama dengan portofolio.

2. Pembentukan Populasi Awal

Pembentukan populasi awal dilakukan dengan membangkitkan sejumlah kromosom secara secara acak sesuai dengan parameter kontrol yang digunakan [4].

3. Evaluasi Fitness

Fitness merupakan nilai yang menyatakan tingkat kebugaran atau kualitas dari sebuah kromosom. Semakin tinggi nilai fitness suatu kromosom maka semakin tinggi pula kromosom dapat bertahan hidup [4]. Evaluasi fitness merupakan tahap untuk menghitung nilai fitness masing-masing kromosom. Nilai fitness diperoleh menggunakan persamaan sebagai berikut [11]:

$$
\text { fitness }=\frac{\bar{R}_{p}}{\sigma_{p}}=\frac{\alpha_{p}+\beta_{p} \bar{R}_{m}}{\sqrt{\beta_{p}{ }^{2} \sigma_{m}^{2}+\left(\sum_{i=1}^{n} w_{i} \sigma_{e_{i}}\right)^{2}}}
$$

dengan $\bar{R}_{p}$ merupakan expected return portofolio dan $\sigma_{p}$ merupakan risiko portofolio.

\section{Seleksi Kromosom}

Kromosom-kromosom dalam populasi selanjutnya diseleksi agar pop size setiap generasi berjumlah konstan. Seleksi dilakukan dengan menggunakan metode elitism yaitu kromosom-kromosom diurutkan berdasarkan nilai fitness nya, kemudian kromosom-kromosom yang masuk dalam 
peringkat sesuai dengan parameter kontrol pop size digunakan sebagai populasi pada generasi berikutnya [11].

5. Crossover

Crossover merupakan tahap untuk menghasilkan offspring dari dua induk yang mewarisi sifat-sifat induknya [4]. Metode crossover yang digunakan dalam penelitian ini adalah extended intermediate crossover. Jumlah kromosom yang akan mengalami proses crossover ditentukan oleh parameter kontrol yang digunakan. Offspring yang dihasilkan dapat menggunakan persamaan berikut ini [11]:

$$
\begin{aligned}
& C_{1}=P_{1}+\alpha\left(P_{2}-P_{1}\right) \\
& C_{2}=P_{2}+\alpha\left(P_{1}-P_{2}\right)
\end{aligned}
$$

dengan $C_{1}$ dan $C_{2}$ merupakan offspring yang dihasilkan dari proses crossover, $P_{1}$ dan $P_{2}$ merupakan induk yang terpilih berdasarkan bilangan acak yang dibangkitkan dan nilai $\alpha$ merupakan nilai yang dibangkitkan pada interval yang telah ditentukan.

6. Mutasi

Mutasi merupakan tahap untuk menghasilkan offspring yang mengubah sifat-sifat atau nilai dari satu atau beberapa gen dalam sebuah kromosom [12]. Pada penelitian ini, mutasi dilakukan dengan mengubah satu nilai gen dari sebuah kromosom. Jumlah kromosom yang akan mengalami proses mutasi ditentukan oleh parameter kontrol yang digunakan.

Pada proses pembentukan populasi awal, proses crossover dan proses mutasi, kromosom bisa saja tidak sesuai dengan constraint yang telah ditetapkan maka kromosom tersebut harus di repair dengan menggunakan persamaan sebagai berikut [11]:

$$
\text { New } \text { gen }_{i}=\frac{i \text { isi gen }_{i}}{\sum_{i=1}^{n} \text { isi gen }_{i}}
$$

dengan isi gen merupakan nilai yang terdapat dalam gen dan $n$ merupakan jumlah gen dalam satu kromosom.

\section{HASIL DAN PEMBAHASAN}

Data yang digunakan dalam penelitian ini berupa data penutupan harga saham bulanan LQ 45 dan data Indeks Harga Saham Gabungan (IHSG) selama periode pengamatan yaitu Januari 2010 sampai Juni 2018 sehingga diperoleh 102 harga penutupan saham bulanan. Data tersebut diperoleh dari http://www.finance.yahoo.com/. Dari 45 saham tersebut terdapat 18 saham yang selalu terdaftar dalam indeks LQ 45. Langkah pertama yang dilakukan adalah menghitung expected return, varians dan standar deviasi masing-masing saham dan IHSG.

Tabel 1 Hasil Perhitungan Expected Return, Standar Deviasi dan Varians Masing-Masing

\begin{tabular}{cccc}
\hline Kode & $\overline{\boldsymbol{R}}_{\boldsymbol{i}}$ & $\boldsymbol{\sigma}_{\boldsymbol{i}}$ & $\boldsymbol{\sigma}_{\boldsymbol{i}}^{\mathbf{i}}$ \\
\hline ADRO & 0,0004 & 0,1098 & 0,0121 \\
ASII & 0,0067 & 0,0709 & 0,0050 \\
BBCA & 0,0155 & 0,0589 & 0,0035 \\
BBNI & 0,0139 & 0,0877 & 0,0077 \\
BBRI & 0,0144 & 0,0814 & 0,0066 \\
BMRI & 0,0110 & 0,0755 & 0,0057 \\
GGRM & 0,0105 & 0,0800 & 0,0064 \\
INDF & 0,0051 & 0,0707 & 0,0050 \\
INTP & 0,0003 & 0,0920 & 0,0085 \\
IHSG & 0,0084 & 0,0480 & 0,0017 \\
\hline
\end{tabular}

\begin{tabular}{cccc}
\hline Kode & $\overline{\boldsymbol{R}}_{\boldsymbol{i}}$ & $\boldsymbol{\sigma}_{\boldsymbol{i}}$ & $\boldsymbol{\sigma}_{\boldsymbol{i}}^{\mathbf{2}}$ \\
\hline JSMR & 0,0096 & 0,0751 & 0,0056 \\
KLBF & 0,0141 & 0,0753 & 0,0057 \\
LPKR & $-0,0026$ & 0,1119 & 0,0125 \\
PGAS & $-0,0075$ & 0,1084 & 0,0118 \\
PTBA & $-0,0124$ & 0,1911 & 0,0365 \\
SMGR & 0,0000 & 0,0791 & 0,0063 \\
TLKM & 0,0076 & 0,0601 & 0,0036 \\
UNTR & 0,0075 & 0,0801 & 0,0064 \\
UNVR & 0,0131 & 0,0715 & 0,0051 \\
\hline
\end{tabular}

Berdasarkan Tabel 1 diperoleh bahwa terdapat 16 saham yang memiliki expected return positif dan 3 saham yang memiliki expected return negatif. Saham-saham yang memiliki nilai expected return 
negatif juga memiliki nilai standar deviasi yang lebih besar dari standar deviasi saham-saham dengan expected return positif. Berdasarkan nilai expected return dan standar deviasi tersebut, maka sahamsaham yang memiliki nilai expected return negatif tidak dijadikan sebagai alternatif dalam melakukan investasi. Dengan demikian, saham-saham LPKR, PGAS dan PTBA tidak masuk dalam analisis berikutnya.

Tahap berikutnya melakukan uji normalitas Kolmogorov-Smirnov, menghitung nilai $E R B$ dan $C u t$ off Rate setiap saham. Berdasarkan Tabel 2, diperoleh hasil uji normalitas Kolmogorov-Smirnov saham-saham tersebut berdistribusi normal. Selanjutnya, menentukan saham-saham yang masuk sebagai kandidat dalam portofolio saham optimal berdasarkan Single Index Model. Penentuan sahamsaham yang terpilih sebagai kandidat portofolio saham optimal diperoleh dengan membandingkan nilai ERB dengan nilai Cut Off Point $\left(C^{*}\right)$ atau nilai Cut off Rate $\left(C_{i}\right)$ tertinggi pada masing-masing saham. Jika nilai $E R B$ dari saham lebih besar atau sama dengan nilai $C^{*}$ maka saham tersebut dapat dijadikan sebagai kandidat portofolio saham optimal. Saham-saham yang terpilih menjadi kandidat portofolio saham optimal dapat dilihat pada Tabel 2 sebagai berikut.

Tabel 2 Perhitungan P-Value, ERB dan Cut off Rate Setiap Saham

\begin{tabular}{cccc}
\hline Kode Saham & $\boldsymbol{P}$-Value & $\boldsymbol{E R B}_{\boldsymbol{i}}$ & $\boldsymbol{C}_{\boldsymbol{i}}$ \\
\hline ADRO & 0,889 & $-0,0429$ & 0,0045 \\
ASII & 0,444 & 0,0034 & 0,0053 \\
BBCA & 0,818 & 0,0205 & 0,0047 \\
BBNI & 0,375 & 0,0259 & 0,0019 \\
BBRI & 0,813 & 0,0240 & 0,0027 \\
BMRI & 0,887 & 0,0127 & 0,0052 \\
GGRM & 0,697 & 0,0339 & 0,0006 \\
INDF & 0,535 & $-0,0003$ & 0,0051 \\
INTP & 0,756 & $-0,0215$ & 0,0045 \\
JSMR & 0,628 & 0,0159 & 0,0049 \\
KLBF & 0,641 & 0,0297 & 0,0013 \\
SMGR & 0,892 & $-0,0149$ & 0,0047 \\
TLKM & 0,792 & 0,0098 & 0,0053 \\
UNTR & 0,749 & 0,0092 & 0,0054 \\
UNVR & 0,136 & 0,0600 & 0,0003 \\
IHSG & 0,055 & & \\
\hline
\end{tabular}

Berdasarkan Tabel 2, diketahui nilai $C^{*}$ sebesar 0,0054 sehingga terdapat 10 saham yang menjadi kandidat portofolio saham optimal. Dalam penelitian ini, saham-saham yang akan dilanjutkan dalam analisis Algoritma Genetika adalah saham-saham yang memiliki nilai ERB tertinggi urutan pertama sampai dengan urutan ketiga yaitu saham UNVR, GGRM dan KLBF. Saham-saham yang telah terpilih, selanjutnya dianalisis menggunakan Algoritma Genetika.

Siklus-siklus dalam Algoritma Genetika yaitu:

1. Pembentukan Kromosom

Kromosom terdiri atas gen-gen berupa saham-saham yaitu saham UNVR, GGRM dan KLBF.

2. Populasi Awal

Populasi awal dibentuk secara acak sesuai dengan ukuran populasi yang digunakan yaitu sebanyak 50 kromosom.

3. Evaluasi Fitness

50 kromosom dari populasi awal dihitung nilai fitness nya masing-masing. Fitness diperoleh dari rasio antara expected return portofolio dan risiko portofolio. 


\section{Crossover}

Jumlah offspring yang diperoleh dari hasil crossover yaitu sebanyak pop size $\times P_{c}=50 \times 60 \%=$ 30 offspring. Induk-induk yang terpillih akan mengalami proses crossover menggunakan metode extended intermediate crossover.

5. Mutasi

Jumlah offspring yang diperoleh dari hasil mutasi yaitu sebanyak pop size $\times P_{m}=50 \times 10 \%=5$ offspring. Hal ini berarti terdapat lima kromosom yang akan diubah satu nilai gen dari masingmasing kromosom.

6. Seleksi

Total kromosom yang diperoleh setelah proses operator Algoritma Genetika dilakukan adalah kromosom-kromosom dari pop size awal, offspring hasil proses crossover dan offspring hasil mutasi yaitu 85 kromosom. Dalam Algoritma Genetika, pop size dari setiap generasi bernilai konstan sesuai dengan parameter kontrol yang digunakan yaitu 50 kromosom maka kromosomkromosom tersebut harus diseleksi. Metode seleksi yang digunakan adalah seleksi elitism, sehingga kromosom-kromosom yang diperoleh adalah kromosom dengan nilai fitness urutan 50 terbesar.

Tahap-tahap tersebut dilakukan sampai dengan kriteria berhenti yang digunakan yaitu generations atau berhenti pada generasi yang telah ditentukan. Pada penelitian ini, simulasi dihentikan sampai dengan generasi ketiga. Berdasarkan hasil perhitungan menggunakan Single Index Model dan Algoritma Genetika bobot portofolio, return portofolio dan risiko portofolio yang diperoleh adalah sebagai berikut:

Tabel 3 Hasil Perhitungan Bobot Portofolio, Return Portofolio dan Risiko Portofolio Berdasarkan Single Index Model dan Algoritma Genetika

\begin{tabular}{cccccc}
\hline \multirow{2}{*}{ Metode } & \multicolumn{3}{c}{ Bobot Portofolio } & Return & Risiko \\
& UNVR & GGRM & KLBF & Portofolio & Portofolio \\
\hline Single Index Model & 0,4126 & 0,2038 & 0,3835 & 0,0075 & 0,0746 \\
Algoritma Genetika & 0,9372 & 0,0326 & 0,0301 & $\mathbf{0 , 0 0 8 1}$ & $\mathbf{0 , 0 7 1 9}$ \\
\hline
\end{tabular}

Berdasarkan Tabel 3, diperoleh bahwa return portofolio dan risiko portofolio Algoritma Genetika lebih optimal dibandingkan dengan Single Index Model.

\section{KESIMPULAN}

Berdasarkan hasil analisis yang telah dilakukan, dapat disimpulkan bahwa:

1. Saham-saham yang masuk dalam portofolio saham optimal untuk dilanjutkan dalam proses Algoritma Genetika adalah saham UNVR, saham GGRM dan saham KLBF. Saham-saham tersebut diperoleh berdasarkan nilai ERB dan Cut Off Point menggunakan perhitungan manual menggunakan Single Index Model. Saham-saham yang memiliki nilai ERB lebih besar atau sama dengan dari Cut Off Point maka saham tersebut dapat dipilih sebagai alternatif untuk berinvestasi. Saham-saham tersebut terdiri atas sebesar 10 saham. Akan tetapi, saham yang digunakan untuk dilanjutkan dalam analisis Algoritma Genetika sebanyak tiga saham yang memiliki nilai ERB tertinggi urutan pertama sampai dengan urutan ketiga.

2. Analisis yang dilakukan bahwa Algoritma Genetika dapat menentukan portofolio saham optimal adalah dengan membandingkan expected return portofolio dan risiko portofolio antara Algoritma Genetika dengan perhitungan manual menggunakan Single Index Model. Expected return portofolio berdasarkan Algoritma Genetika sebesar 0,0081 lebih besar dari expected return perhitungan manual menggunakan Single Index Model yaitu 0,0075 dan risiko portofolio berdasarkan Algoritma Genetika sebesar 0,0719 lebih kecil dibandingkan dengan risiko portofolio perhitungan manual menggunakan Single Index Model yaitu sebesar 0,0746. Sehingga Algoritma 
Genetika lebih optimal dibandingkan dengan perhitungan manual menggunakan Single Index Model. Bobot atau proporsi dana yang dapat dialokasikan oleh investor adalah sebesar 93,73\% pada saham UNVR, 3,26\% pada saham GGRM dan 3,01\% pada saham KLBF.

\section{DAFTAR PUSTAKA}

[1] Halim A. Analisis Investasi. Jakarta: Salemba Empat; 2005.

[2] Husnan S. Dasar-Dasar Teori Portofolio dan Anallisis Sekuritas. Yogyakarta: AMP YKPN; 2003.

[3] Sutojo T, Mulyanto E, Suhartono V. Kecerdasan Buatan. Yogyakarta: ANDI; 2011.

[4] Zukhri Z. Algoritma Genetika. Yogyakarta: ANDI; 2014.

[5] Hartono J. Teori dan Praktik Portofolio dengan Excel. Jakarta: Salemba Empat; 2014.

[6] Herlianto D. Manajemen Investasi Plus Jurus Mendeteksi Investasi Bodong. Yogyakarta: Goyson Publishing; 2013.

[7] Siegel S. Nonparametric Statistics For The Behavioral Sciences, New York: The Mc Graw-Hill Companies; 1956.

[8] Hartono J. Teori Portofolio dan Analisis Investasi. Yogyakarta: BPFE; 2015.

[9] Elton EJ, and Gruber MJ. Modern Portofolio Theory and Investment Analysis. Canada: John Willey \& Sons, Inc. Toronto; 1995.

[10] Syarif, E.A. Algoritma Genetika: teori dan aplikasi. Yogyakarta: Graha Ilmu; 2014.

[11] Wahyuni R, Mahmudy WF, Setiawan, DB. Penentuan Portofolio Saham Optimal Menggunakan Algortima Genetika. Jurnal Pengembangan Teknologi Informasi Dan Ilmu Komputer, 2017; 1(1):63-68.

[12] Hopgood AA. Intelligent Systems for Engineers and Scientists. Florida: CRC Press; 2001.

EKA LESTARI

EVY SULISTIANINGSIH

NURFITRI IMRO’AH
: Jurusan Matematika FMIPA UNTAN, Pontianak

ekalestarie106@gmail.com

: Jurusan Matematika FMIPA UNTAN, Pontianak

evysulistianingsih@math.untan.ac.id

: Jurusan Matematika FMIPA UNTAN, Pontianak nurfitriimroah18@gmail.com 